\title{
The Integrated Approach to Seismic Attributes of Lithological Characterization of Reservoirs: Case of the F3 Block, North Sea-Dutch Sector
}

\author{
Oumarou Sanda ${ }^{1,2 *}$, Djeddi Mabrouk ${ }^{3}$, Tabod C. Tabod ${ }^{4,5}$, \\ Jean Marcel1,4, Jean M. Abate Essi' ${ }^{6}$, Simon Ngos III ${ }^{7}$ \\ ${ }^{1}$ National Institute of Cartography, Yaoundé, Cameroon \\ ${ }^{2}$ Department of Physics, Faculty of Science, University of Maroua, Maroua, Cameroon \\ ${ }^{3}$ Department of Geophysics, Faculty of Hydrocarbons and Chimistry, M’Hamed Bougara University of Boumerdès, Boumerdès, \\ Algeria \\ ${ }^{4}$ Department of Physics, Faculty of Science, University of Yaoundé 1, Yaoundé, Cameroon \\ ${ }^{5}$ Department of Physics, Faculty of Science, University of Bamenda, Bamenda, Cameroon \\ ${ }^{6}$ Ore Processing Laboratory, Institute for Geological and Mining Research, Nlongkak Yaoundé, Yaoundé, Cameroon \\ ${ }^{7}$ Department of Exploration, Faculty of Mining and Petroleum Industries, University of Maroua, Kaélé, Cameroon \\ Email: *oumarousanda22@gmail.com, djeddimabrouk@yahoo.com, ctabod@gmail.com, \\ jmarcel02@yahoo.fr, abatemarcel@yahoo.fr, sngos@yahoo.com
}

How to cite this paper: Sanda, O., Mabrouk, D., Tabod, T.C., Marcel, J., Essi, J.M.A. and Ngos III, S. (2020) The Integrated Approach to Seismic Attributes of Lithological Characterization of Reservoirs: Case of the F3 Block, North Sea-Dutch Sector. Open Journal of Earthquake Research, 9, 273-288.

https://doi.org/10.4236/ojer.2020.93016

Received: March 8, 2020

Accepted: May 16, 2020

Published: May 19, 2020

Copyright $\odot 2020$ by author(s) and Scientific Research Publishing Inc. This work is licensed under the Creative Commons Attribution International License (CC BY 4.0).

http://creativecommons.org/licenses/by/4.0/

\begin{abstract}
Technological development, particularly the development of signal processing, has contributed to the improvement of the quality of results in the analysis of the characteristics of hydrocarbon reservoirs. This scientific advance is especially marked by the introduction of seismic attributes in the characterization of reservoirs. This paper is aimed at evaluating the contribution of seismic attributes in the lithological characterization of hydrocarbon accumulation zones. Thus, it has been found that instantaneous attributes make it possible to highlight the different properties of reservoir rocks. Techniques for extracting three-dimensional volume attributes have been applied to a 3D seismic data volume of the F3 block in the Dutch sector of the North Sea. The purpose of using these volume attributes is to extract signal characteristics from lithofacies in hydrocarbon zones. The results provide a remarkable contribution to instantaneous seismic attributes in reservoir location, hydrocarbon detection, and reservoir lithological prediction. The instantaneous amplitude, the derivative of amplitude 1, the factor $Q$, the energy and the Hilbert transform are attributes which highlight the presence of hydrocarbons through the bright spots. Thus, curvature, similarity, dip, and coherence are useful in the determination of traps such as faults and anticlines. The crossing of the instantaneous amplitude and the instantaneous frequency makes it possible
\end{abstract}


to analyze the lithofacies. In the same way, the analysis of the crossed diagrams between the porosity and the instantaneous amplitude made it possible

to define the different layers of the reservoir.

\section{Keywords}

Seismic, Seismic Attributes, Characterization, Lithology, Reservoir

\section{Introduction}

A seismic attribute is a quantitative measure of a seismic characteristic of interest [1]. Seismic attributes are data or information obtained from seismic data, either by direct measurements, or by logical or experience-based reasoning [2]. Effective seismic attributes can lead to better geological or geophysical interpretation of the data and provide a better understanding of the geometry and physical properties of the subsoil. Today, there are hundreds of analytical attributes used to analyze the subsoil. Thus, [3] listed more than three hundred attributes. But, according to their method of calculation and their physical properties, [4] proposed two major types of attributes namely geometric attributes and physical attributes. For physical attributes, we distinguish between wavelet attributes and instantaneous attributes. In his works, [5] evoked the existence of sixteen (16) instantaneous attributes. These attributes each have a particularity in the analysis of the properties of the subsoil.

This article aims to build an approach for the lithological characterization of reservoirs using seismic attributes. To do this, the 3D seismic data from block F3 was used for an application and the results obtained were developed while making a comparison with other reservoir characterization methods.

\section{Materials and Methods}

The use of seismic attributes [6] in oil exploitation has become common since the publication of [7] and today there is a growing use of attributes in reservoir analysis. Despite the existence of a multitude of seismic attributes, the construction of an integrated approach to reservoir analysis remains a major challenge for understanding the characteristics of the accumulation zones (Figure 1). To do this, it is therefore important to test and select the attributes based on their effectiveness in a specific area. In this work, it is therefore a question of first identifying the hydrocarbon zones using attributes such as instantaneous amplitude, energy, quality factor and instantaneous frequency. Then, the localization of the traps which make it possible to delimit the reservoirs with attributes such as curvature, coherence, dip and similarity. Finally, the analysis of the seismic facies is an important step which makes it possible to make a lithological prediction by well-selected attributes namely the acoustic impedance, lambda, mhu and the $\mathrm{Vp} / \mathrm{Vs}$ ratio. Thus, an analysis based on the combination of attributes and 
crossplotting of data is used to deepen the lithological study of the reservoirs.

The data used in this work was derived from block F3 covering an area of about $16 \times 23 \mathrm{~km}^{2}$ in the Dutch sector of the North Sea (Figure 2). The block is covered by $3 \mathrm{D}$ seismic acquired to explore the oil and gas deposits in Upper Jurassic-Lower Cretaceous strata, which lie below the range selected for this demonstration. The data volume consists of 646 in-lines and 947 cross-lines. The line spacing is $25 \mathrm{~m}$ for line and cross lines, and the sampling rate is $1 \mathrm{~ms}$. A standard

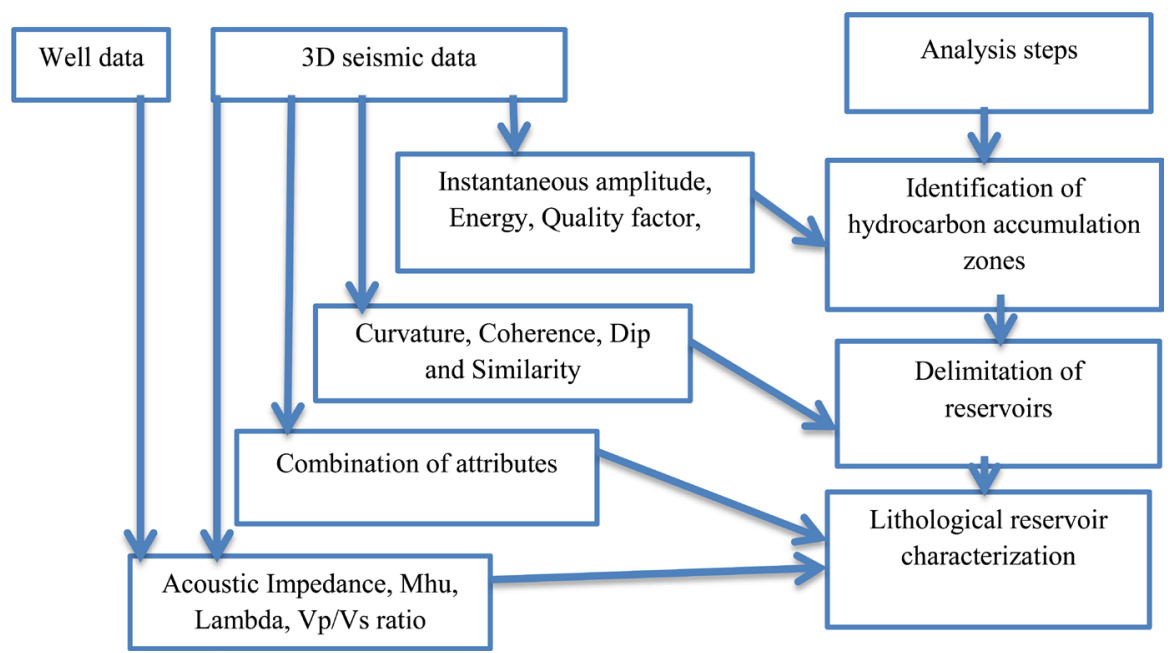

Figure 1. Methodology diagram.

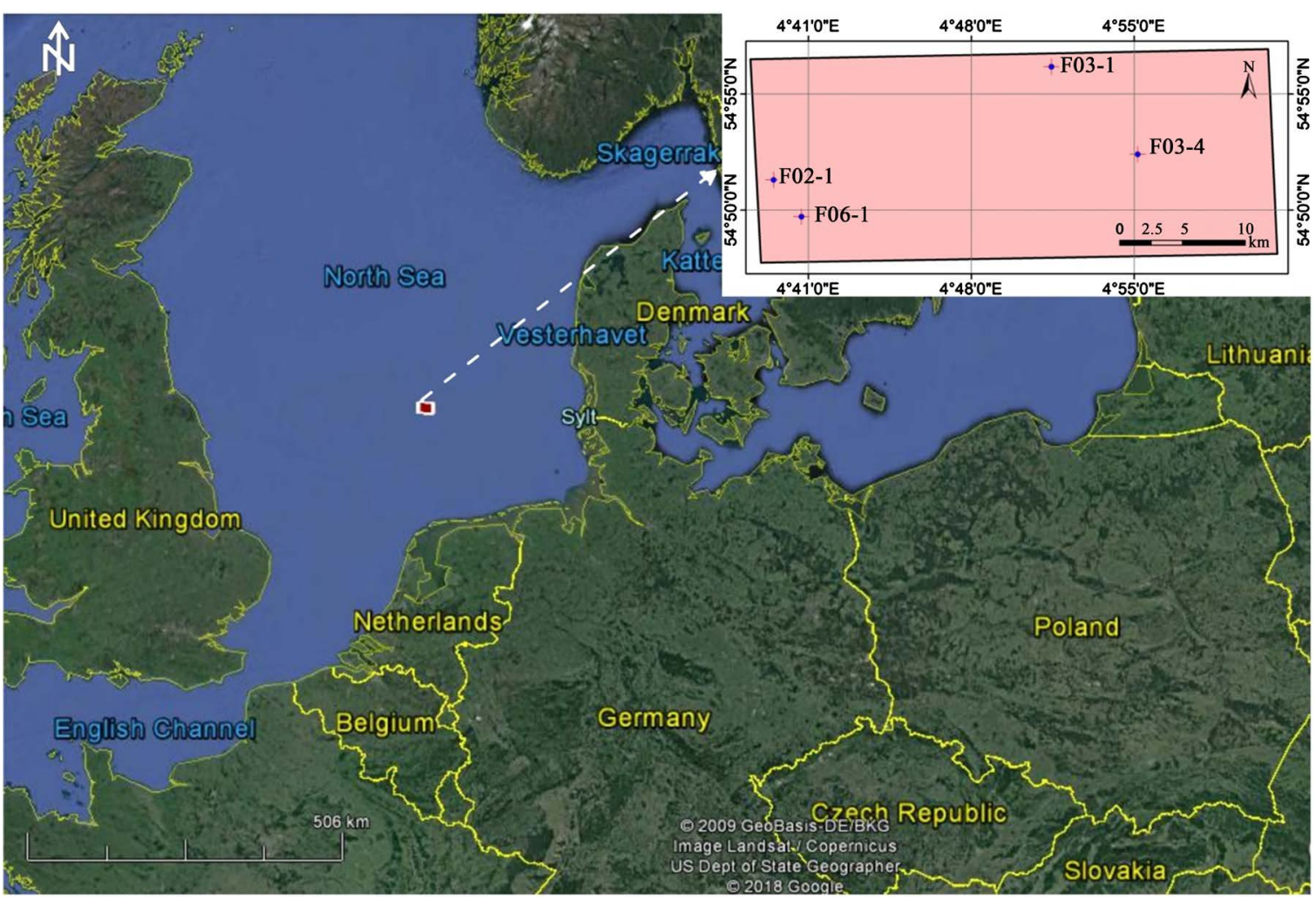

Figure 2. Location of the F3-Block in the North Sea (Dutch sector) with its wells (F02-1, F03-1, F03-4 and F06-1) presented on Google Earth. 
seismic data processing sequence has been applied to the data. Data from four wells in the region were available, in particular the actual depth logs, including sonic and gamma logs. Density logs were reconstructed from sonic logs using neural network techniques. Sonic logs were also used to calculate porosity logs for all wells. In the survey, four vertical wells are present (F02-1, F03-2, F03-4 and F06-1) with sonic and gamma logs but only two wells (F02-1 and F03-2) have density logs.

\section{Results}

The attributes are very numerous today, counting them is an arduous activity and their use is varied and depends on the objectives set for a given study. The selection of attributes made it possible to make a lithological analysis of the hydrocarbon reservoirs. Thus, the results obtained are divided into three groups which are the identification of the hydrocarbon accumulation zones, the delimitation of the reservoirs through the hydrocarbon traps and the lithological analysis of the layers constituting the reservoirs.

\subsection{Identification of Hydrocarbon Accumulation Zones}

The detection of the hydrocarbon accumulation zones was carried out thanks to the attributes which presented results of superior quality. Thus, attributes such as instantaneous amplitude, Q factor, energy, average amplitude allowed everyone to highlight the light points that reflect the presence of hydrocarbons on the seismic section. While there is a difference between these attributes, they all highlight the same bright spots. This presence is proven by calculating the instantaneous amplitude through light points (Figure 3). In the same order, the quality factor and the energy also present bright spots which highlight the presence of hydrocarbons (Figure 4), which probably reflects the implication of this attribute in the detection of hydrocarbons. Thus, seismic attributes are used as predictive variables in lithological prediction and the characterization of reservoirs [8]. The amplitude maps (Figure 3) show the spatial extent of the light points (black color) by associating the three components of the data, namely the line in line, the line crossed and the slice $z$. The identification of the light points was done using the online section but it is also possible to do it with cross sections. The z-section is necessary in this analysis because it confirms the existence of a reservoir by giving an overview of the hydrocarbon zone (Figure 3 ) through a black layer.

\subsection{Delimitation of Reservoirs through Hydrocarbon Traps}

The determination of the structures which delimit the zones of hydrocarbons can be done by instantaneous attributes. It is in this sense that [5] states that these amplitude maps are very useful to delimit possible zones of hydrocarbon accumulations. Attributes such as cosine phase, instantaneous frequency, instantaneous phase and instantaneous weighted phase can be used to detect the 
faults which constitute the traps of the identified reservoirs. As these attributes do not provide good results for identifying traps, the use of attributes such as curvature, coherence, similarity and dips have helped to highlight the traps which delimit the hydrocarbon accumulation zones. Thus, by observing the seismic horizons well, we note that there are offset of the reflectors over a good part of the seismic section (Figure 3). This offset of the reflectors indicates the presence of normal faults which are better-visualized reservoirs to the attributes. The network of faults that is so apparent in the attribute map shown in Figure 5
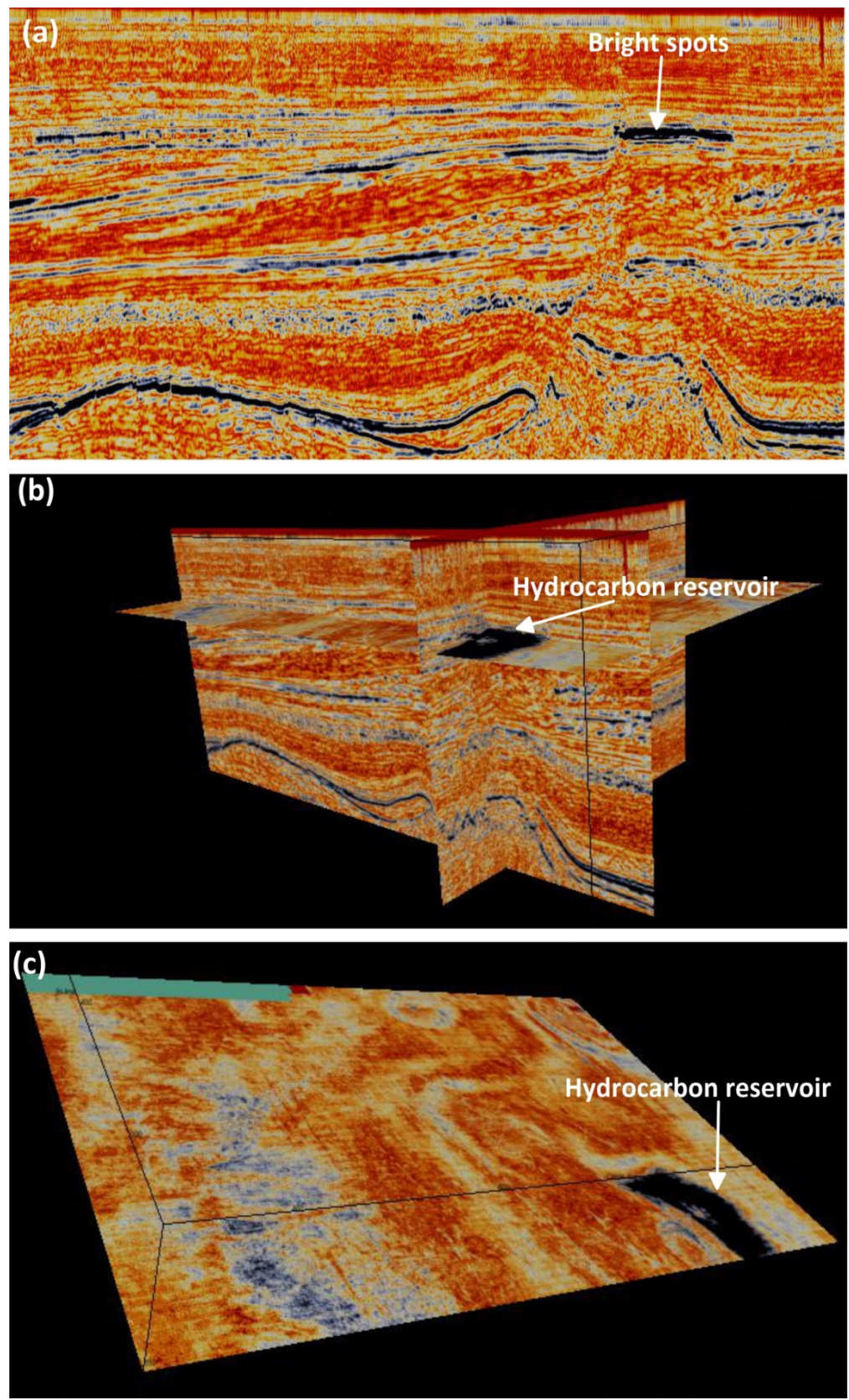

Figure 3. (a) Instantaneous amplitude of in-line 230, (b) the three components of 3D seismic data which are in-line, cross-line and z-slice to show the extent of the reservoir in space, (c) the hydrocarbon reservoir seen by z-slice 524 . 


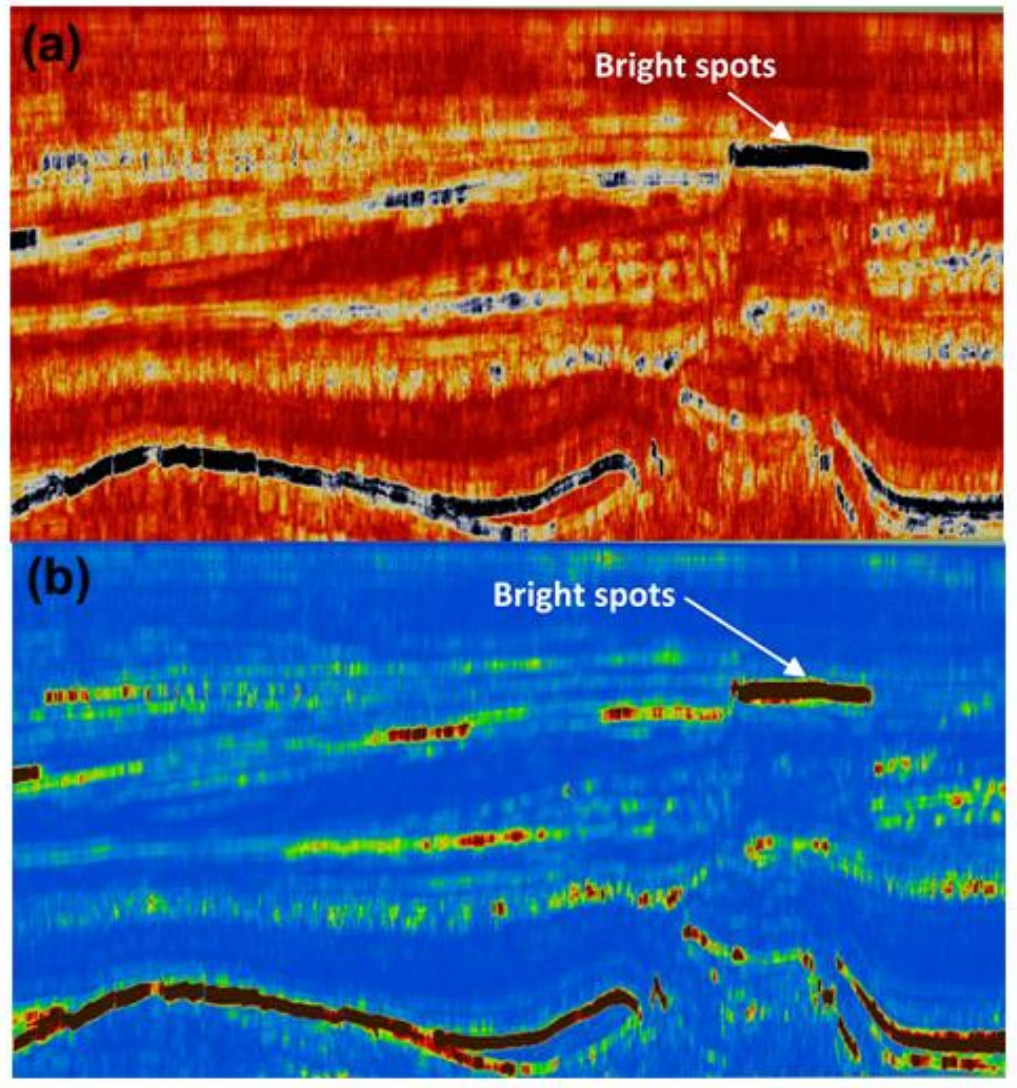

Figure 4. Detection of reservoir by (a) Instantaneous quality factor (in-line 230) and (b) Energy attribute showing bright spots.
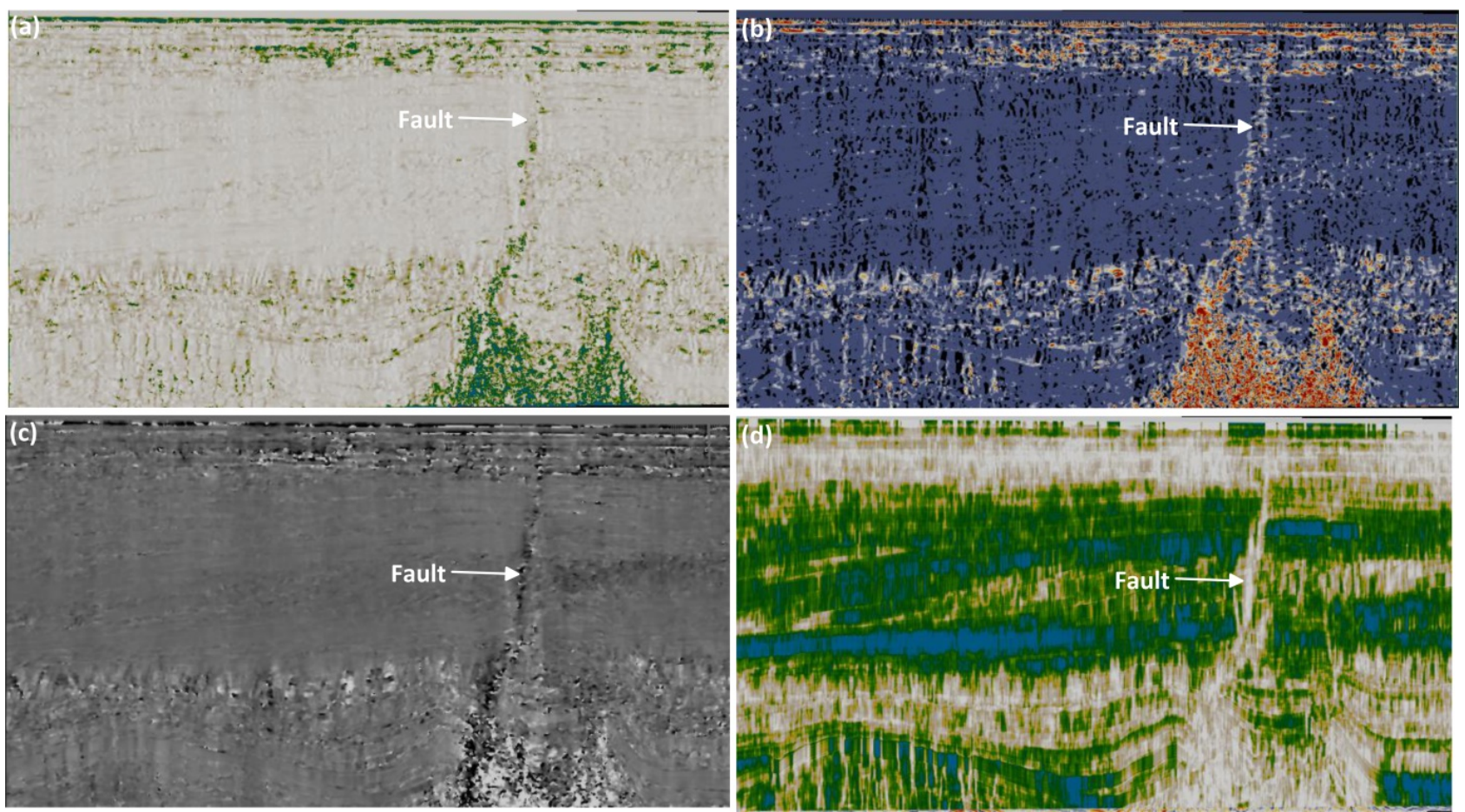

Figure 5. Illustration of faults, (a) most positive curvature, (b) most negative curvature, (c) dip steering, (d) cube similarity. 
shows the implication of attributes such as most positive curvature, most negative curvature, dip steering and cube similarity in the determination of faults. After the location of the reservoirs, the attributes are very useful in the lithological analysis of the reservoirs by crossing the attributes first. Then, the crossing of the well data with the instantaneous attributes and finally a combination of the real data only to confirm the results obtained with the attributes.

\subsection{Lithological Analysis of the Reservoir Layers}

This part includes three stages namely the lithological analysis by seismic attributes, the lithological analysis by attributes with well data and the lithological analysis using only Well data.

\subsubsection{Lithological Analysis by Seismic Attributes}

The combination of instantaneous attributes is an approach that makes it possible to predict the nature of the layers constituting the reservoirs. Thus, it is a question here of crossing the attributes which have a strong correlation and involved in the estimation of the lithology. Figure 6(a) illustrates a cloud of dense points for small values of the instantaneous amplitude and values between 12 and $80 \mathrm{~Hz}$ of dominant frequency. This explains the existence of a facies (blue color) well distributed in the seismic section. Despite, the domination of the blue color among the facies, we note the existence of three other facies represented here by the colors green, yellow and red. The intersection of the instantaneous amplitude and the dominant frequency appears as a tool with a strong correlation $(r=0.8)$ which makes it possible to discriminate the different facies. Likewise, the intersection of the instantaneous amplitude attributes and the $\mathrm{Q}$ factor presents the dense point cloud for very low values and the higher the values the more points are scattered. This implies a strong resemblance between the instantaneous amplitude and the $\mathrm{Q}$ factor for low values (Figure 6(b)). This similarity is justified by the correlation $(r=0.62)$ between these two attributes. Regarding the discrimination of lithofacies, we find the same facies in both crosses (Figure 6 and Figure 7) but it is in their distribution that there is a difference that is probably due to the characteristics of each attribute.

The work of [9] marks the beginning of the use of instantaneous frequency in the characterization of reservoirs, but [10] has shown the implication of this attribute in the analysis of lithofacies by crossing the instantaneous frequency with the amplitude first and then with the thin bed indicator. The use of attributes in lithological forecasting appears to be an interesting approach to other methods based on direct measurements from rock samples from the study area and real data. The contribution of instantaneous attributes to the lithological characterization of reservoirs is important because it is possible to obtain lithofacies by combining several attributes in order to have multi-attributes. Thus, the amplitude, the amplitude $1^{\text {st }}$ derivative, the dominant frequency, the $\mathrm{Q}$ factor, the amplitude average and Hilbert transform were combined to predict the nature of the rocks. Thus, this multi-attribute obtained illustrates the different 

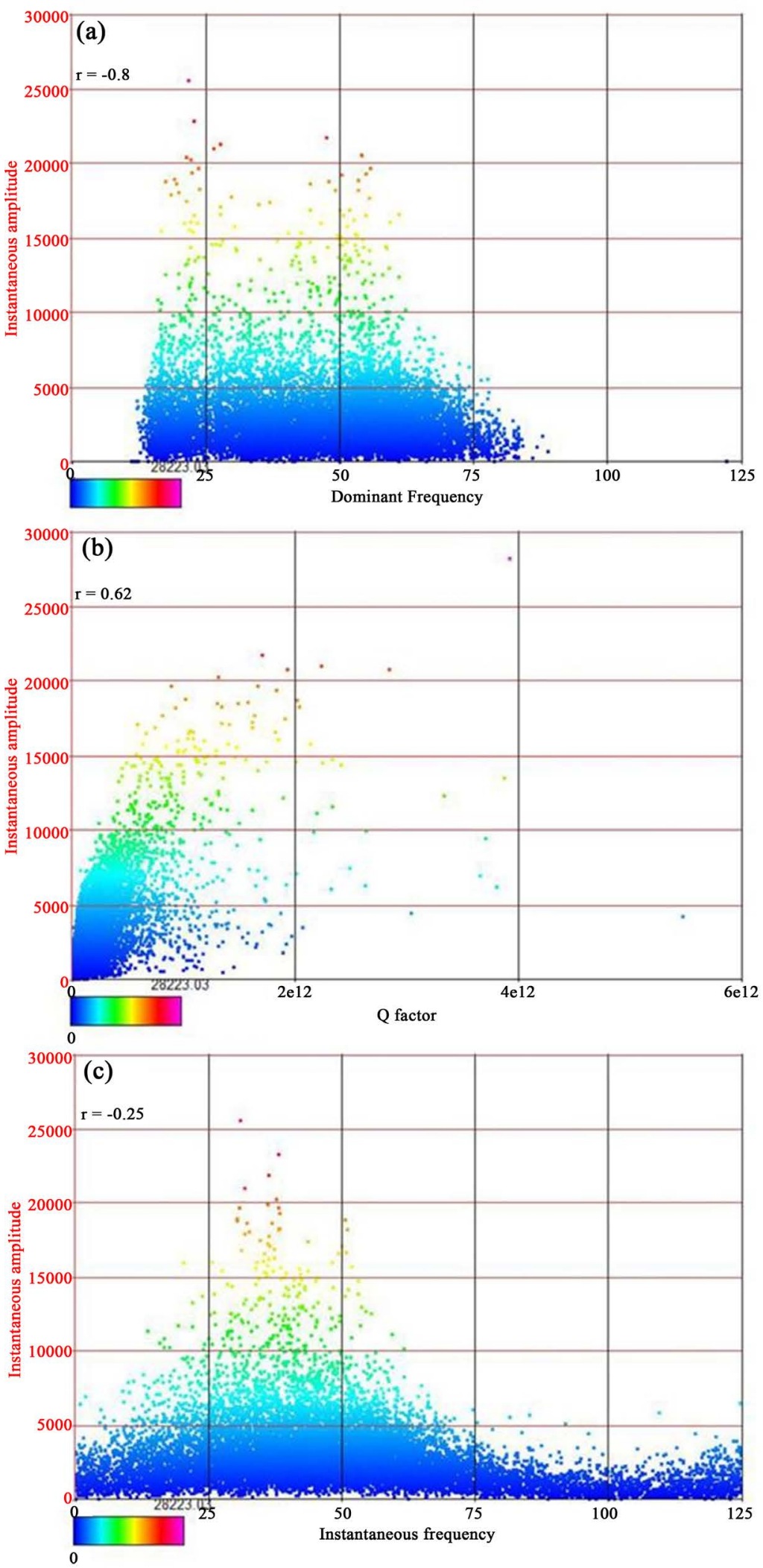

Figure 6. Diagrams of crossplotting, (a) Instantaneous amplitude and dominant frequency, (b) Instantaneous amplitude and quality factor, (c) Instantaneous amplitude and Instantaneous frequency. 


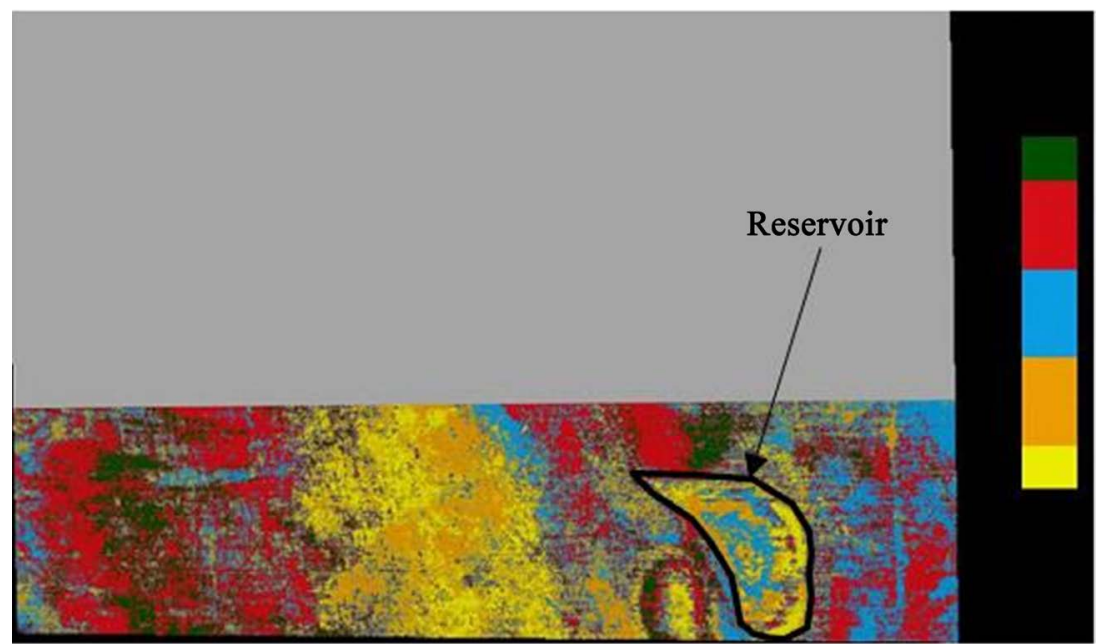

Figure 7. Multi attribute composed of seven attributes which are amplitude, Q factor, Hibert transform, amplitude average, dominant frequency, energy and the amplitude $1^{\text {st }}$ derivative

facies of the reservoir on the section of section Z 524 (Figure 7). The facies corresponding to each color shows the lithological changes in the seismic section and more precisely on the reservoir. From yellow to green through gray, blue and red, we are focused on the number of possible layers to identify in this section.

\subsubsection{Lithological Analysis by Attributes with Well Data}

Porosity is one of the most important properties of the reservoir because it permits to describe the layers that constitute the hydrocarbon accumulation zone. This involves crossing the well data with instantaneous attributes to analyze the lithological changes. To do this, some attributes were selected taking into account their contribution to the lithological discrimination analysis. Thus, the instantaneous amplitude and quality factor were chosen to cross with porosity using the well porosity $\log$ F02-1 (with values between $20 \%$ and $60 \%$ ). Two crossed diagrams were obtained namely the diagram of the porosity and the instantaneous amplitude and that of the porosity and the quality factor (Figure 8(a) and Figure 8(b)). In Figure 8(a), there is a difference in colors that reflect a lithological discrimination through the cross diagram between the instantaneous amplitude attribute and porosity. A good positive correlation is observed and a variation of the porosity on section z-slices 524 . Thus, the blue color has porosity between $22 \%$ and $30 \%$, the light blue with values between $30 \%$ and $35 \%$, the green of $35 \%$ to $40 \%$, yellow with a porosity of $40 \%$ to $48 \%$ and red from $48 \%$ to $58 \%$. Taking into account the regional geology and previous work on porosity, the different colors represent the following lithologies: the blue color for sandstones of the reservoir, the green color for the clays, the yellow color for the unconsolidated sands and the color red for limestones.

In the same order of ideas, the attributes deduced from the impedance such as $\lambda \rho, \mu \rho, \mathrm{Vp} / \mathrm{Vs}$ ratio make it possible to predict the different layers of the reservoir. It is in this sense that we observe a good correlation $(\mathrm{r}=0.7)$ between $\mu \rho$ 

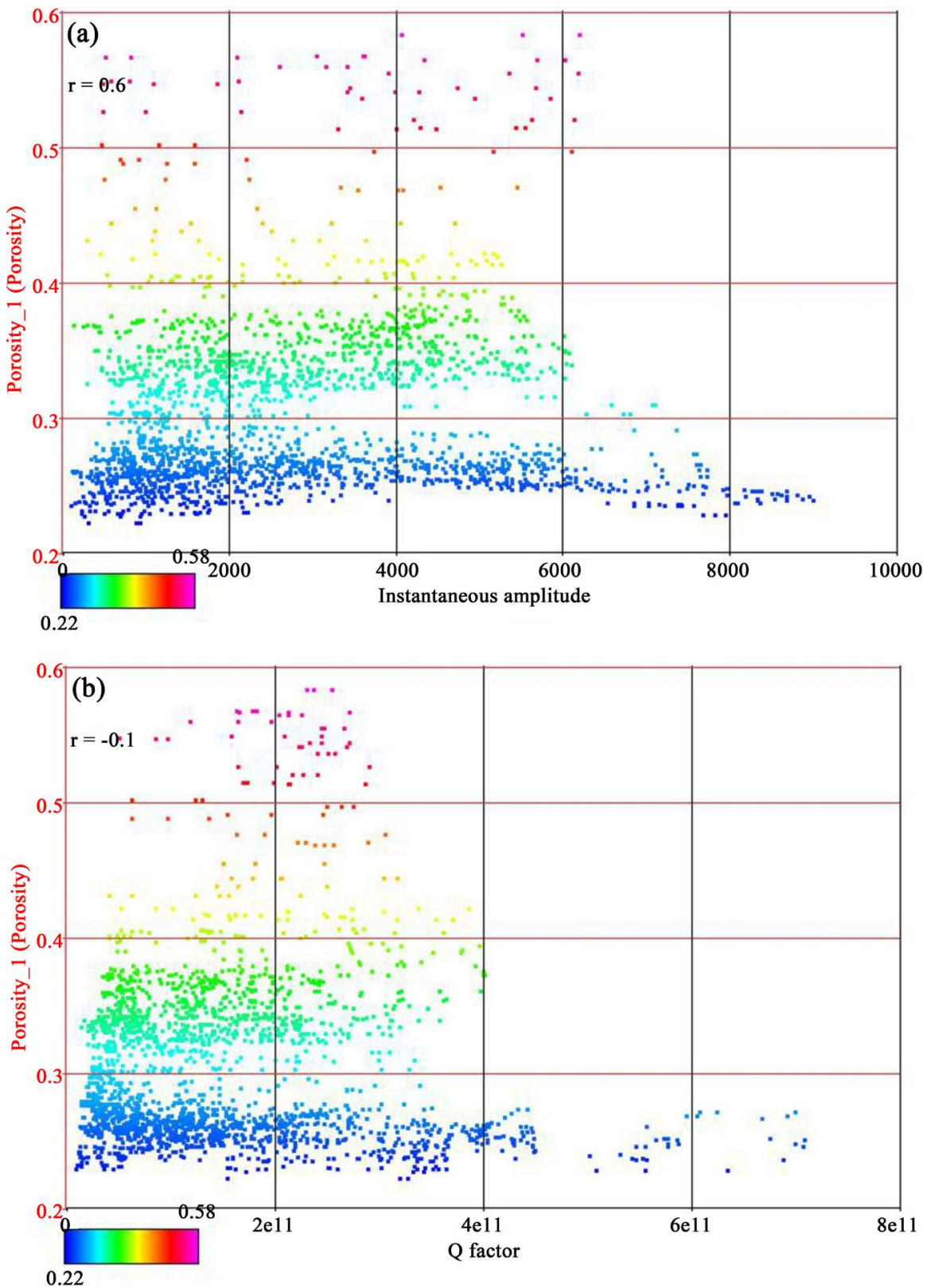

Figure 8. Diagrams of crossplotting (a) well data (F02-1) porosity and instantaneous amplitude, (b) well data (F02-1) porosity and quality factor.

and $\lambda$ and that the crossing of these two attributes (Figure 9) presents the same facies obtained in Figure 8.

\subsubsection{Lithological Analysis Using Only Well Data}

Well data provides real values of several properties such as porosity, acoustic impedance, gamma rays, density, and sometimes permeability. After identifying the accumulation zone and analyzing the lithofacies, crossing the well data confirms the results obtained at the crossing of the instantaneous attributes in order to predict the lithology. To do this, the impedance porosity was crossed at first and later on the porosity to gamma rays. 


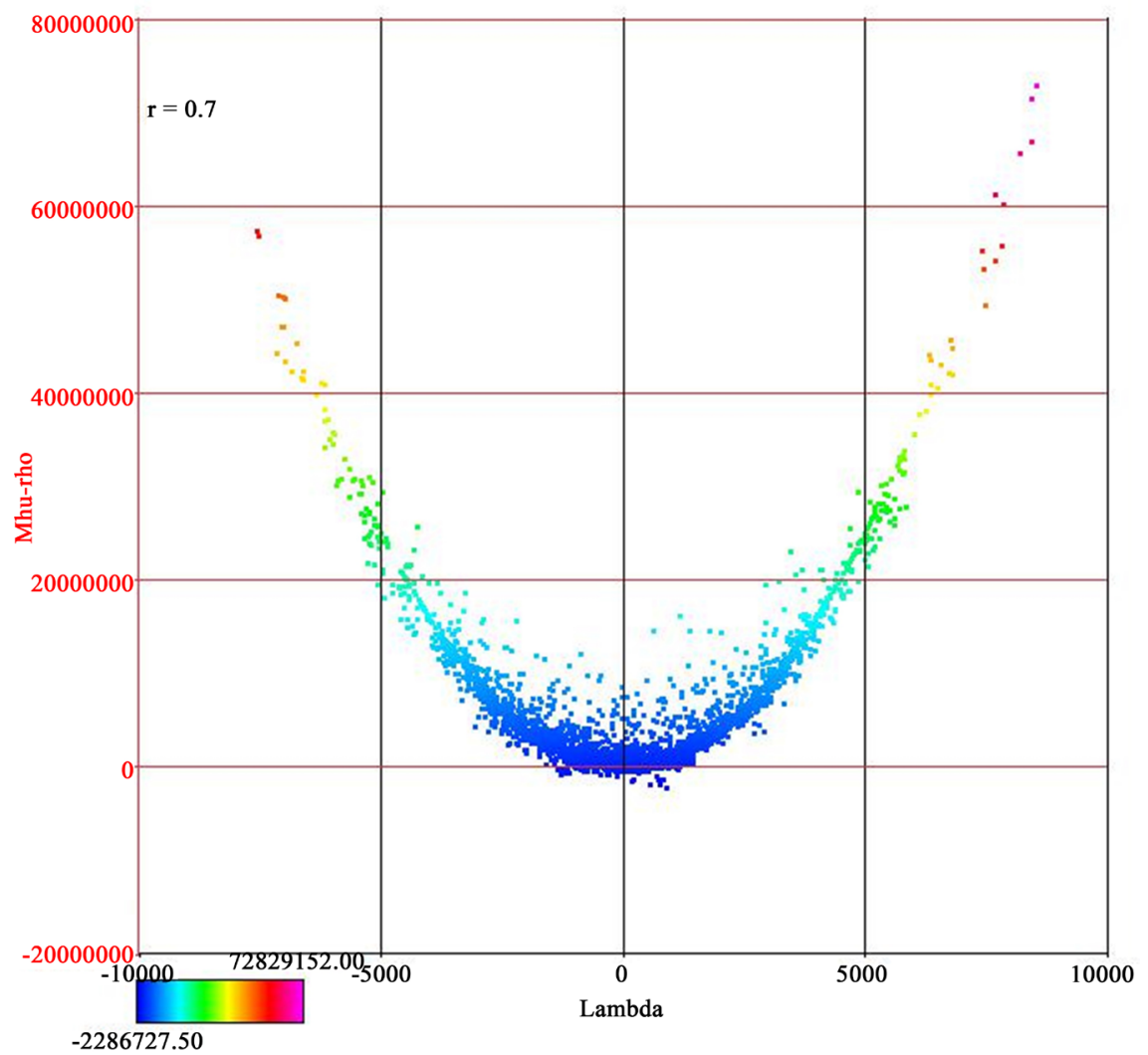

Figure 9. Crossplotting Mhu-rho $(\mu \rho)$ and lambda $(\lambda)$.

Several studies [10] [11] [12] [13] [14] have made it possible to analyze cross-plots between porosity and acoustic impedance to define the different layers. Similarly, some authors [15] [16] [17] [18] have shown that the crossover between the impedance $\mathrm{P}$ and the ratio $\mathrm{Vp} / \mathrm{Vs}$ allows to define a zone of accumulation or not. It is important to note that the bivariate cross-plots from the wells showed the lithofacies. Figure 9 and Figure 10 show two crossplottings which are the porosity-gamma ray diagram and the porosity-impedance $\mathrm{P}$ diagram in order to present the different layers. Thus, Figure 10 shows the different facies observed in the calculated seismic attributes (Figure 3). By taking values of these two variables, from blue to green we have clays or shale's, yellow represents sandstones and red alternate's sand and sandstone. [19] demonstrated the lithological variation depends on the values of the impedance. For them, the weak impedances correspond to the shale's, the moderate impedances to the clayey sandstones and the impedances raised to the exposed sandstones. As for Figure 11 , the correlation between the porosity and the gamma rays is very strong and red densification is observed in the range $25 \%$ to $44 \%$ porosity and from 0 to 125 API gamma rays. This red color represents the layer.

It is also possible to make a three-dimensional cross-section of the porosity, impedance and gamma rays where the different lithologies appear as a function of the porosity and impedance values, in which the low values indicate the zones with shale's and high values refer to sandstone. 


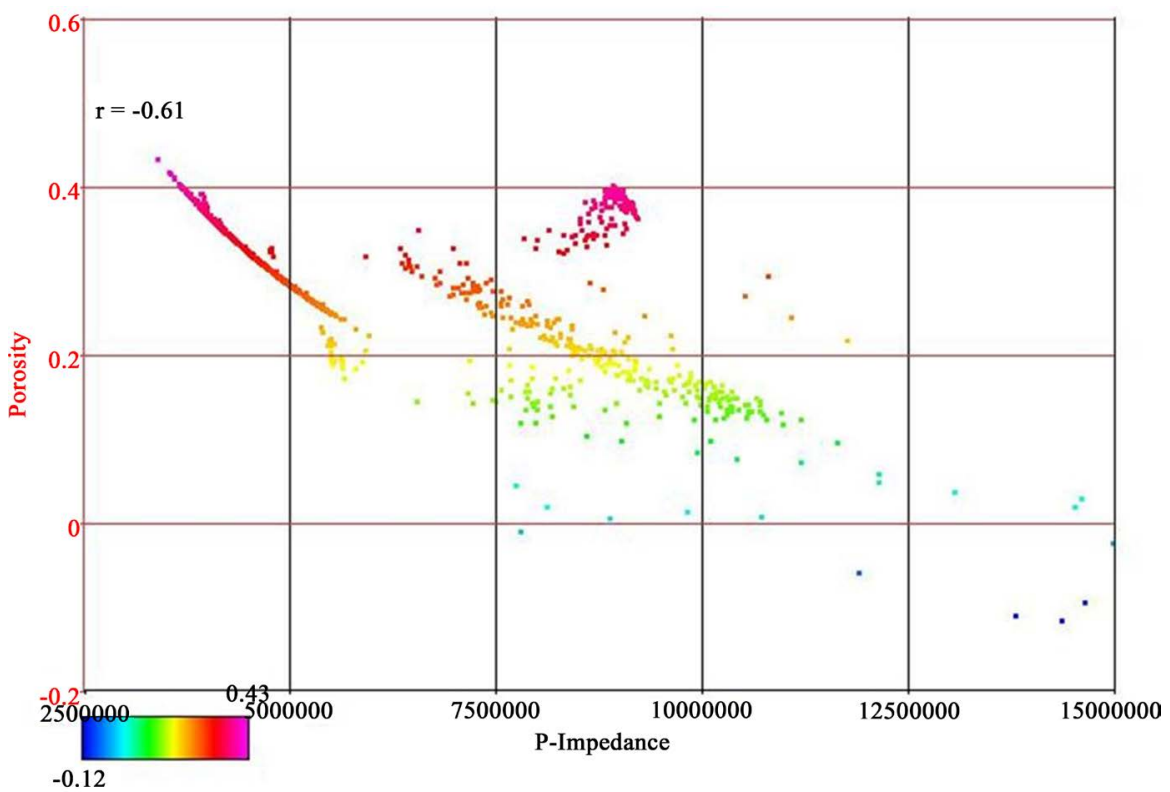

Figure 10. Crossplotting porosity-P-impedance F03-2.

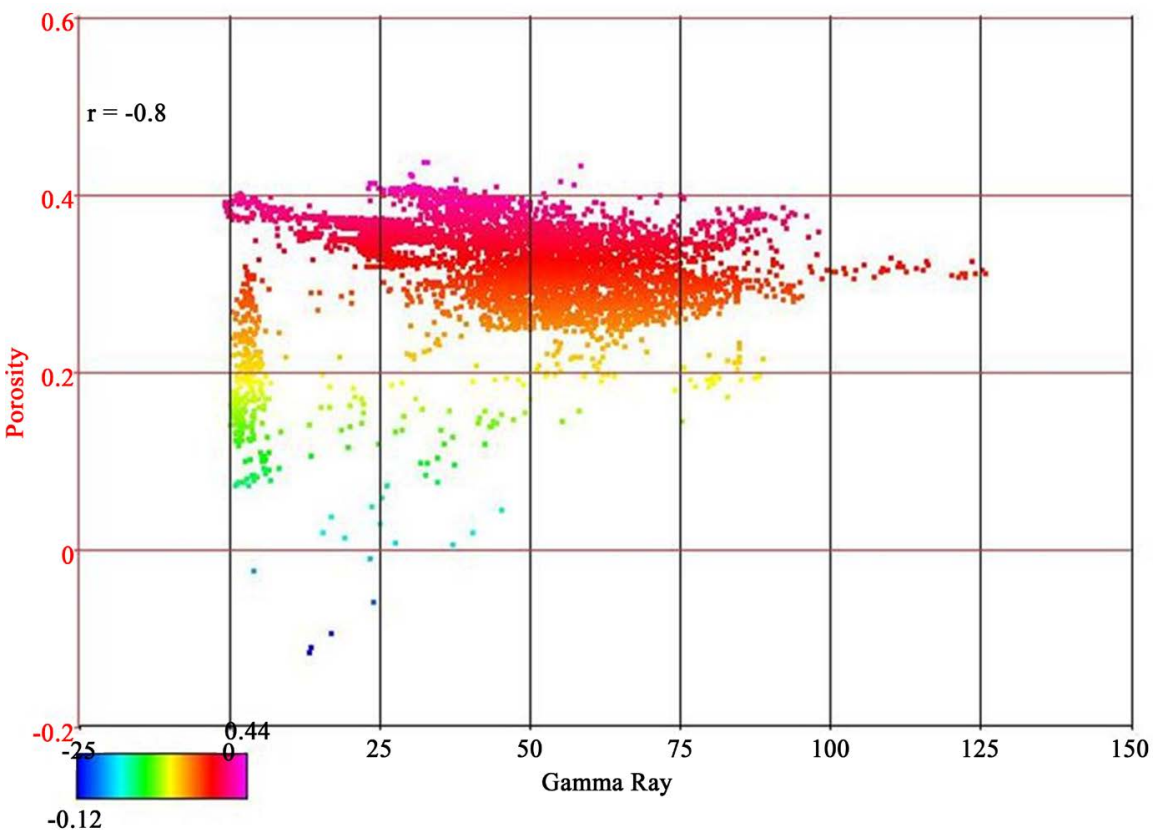

Figure 11. Crossplotting porosity-gamma ray F03-2, F03-4, F06-1.

\section{Discussion}

The approach used in this paper, which incorporates the use of instantaneous attributes in the analysis of lithological changes, proves to be an appropriate method for lithological characterization of hydrocarbon reservoirs. This characterization can be confirmed using other methods such as neuron analysis, co-kriging, and AVO method and meta-attribute approach.

The identification of accumulation zones made by attributes such as instantaneous amplitude, energy attribute and $\mathrm{Q}$ factor through bright spots is efficient 
but geostatic methods such as neural networks, kriging and meta-attributes are techniques based on the conjugation or combination of several attributes chosen according to their convergence in the analysis. So these methods appear as an approach that confirms the results obtained with single attributes. It is in this sense that the authors [20]-[25] analyzed hydrocarbon accumulation zones using the neural network method with a multitude of attributes. This technique appears as a confirmation of methods using one or two seismic attributes in reservoir characterization. It is for this reason that it is widely used to analyze lithofacies.

Similarly, the AVO technique [26] is very much in demand in the lithological analysis of reservoirs because of the quality of the results it presents in the lithological discrimination [27] [28] [29] [30].

The lithological estimation [31] [32] made by seismic attributes is necessary since it permits the orientation of the studies to use the actual data (well log) for confirmation. Since logs provide point information, it is important to note that only seismic attributes allow not only lithological prediction but also interpolation of well data to estimate the distribution of values of porosity, permeability, the saturation, the thickness of the layers on a given area.

\section{Conclusions}

The results show a remarkable contribution of the use of seismic attributes in the lithological characterization of hydrocarbon reservoirs which begins by first detecting the hydrocarbon zones on a seismic section through bright spots, then delimitation of reservoirs through hydrocarbon traps and finally the lithological analysis using seismic and well log. Thus, attributes such as instantaneous amplitude, energy, and Q-factor are best suited to highlight bright spots that are major features of hydrocarbon zones. For the detection of hydrocarbon zones, those attributes also provide a good visualization of the bright spots that most often reflect the presence of hydrocarbons.

Curvature, similarity, dip, and coherence are the most appropriate attributes in identifying traps. As for the lithological analysis, creating a multi attribute from attributes such as amplitude, $Q$ factor, Hibert transform, amplitude average, dominant frequency, energy and the amplitude $1^{\text {st }}$ derivative allows to highlight the facies of the reservoir. The different colors that appear in the accumulation zone represented the different layers of the reservoir. Thus, the crossplotting of attributes between them and attributes with the well log makes it possible to make a prediction of the nature of the layers. Crossplotting well data confirms results obtained with the attributes.

This approach can be adapted to the characterization of the focus in order to predict the earthquake. The detection of the earthquake is based on the maximum amplitude of the $\mathrm{P}$ wave. By definition, the magnitude is a logarithmic of a Wood-Anderson type seismometer on the maximum amplitude of the $\mathrm{P}$ wave. Thus, we note that the first stage of characterization of the earthquake and of the hydrocarbon accumulation zones is essentially based on the measurement of the 
maximum amplitude. We note in both cases that the detection of faults is very important.

\section{Acknowledgements}

The authors would like to acknowledge the dGB Earth Sciences for providing the Opendtect software and the OpendTect Share Seismic Data repository for downloading the seismic and well log data.

\section{Conflicts of Interest}

The authors declare no conflicts of interest regarding the publication of this paper.

\section{References}

[1] Chopra, S. and Marfurt, K.J. (2005) Seismic Attributes: A Historical Perspective. Geophysics, 70, 3-28. https://doi.org/10.1190/1.2098670

[2] Cao, J.H., et al. (2015) Subsurface Channel Detection Using Color Blending of Seismic Attribute Volumes. International Journal of Signal Processing, Image Processing and Pattern Recognition, 8, 157-170. https://doi.org/10.14257/ijsip.2015.8.12.16

[3] Chen, Q. and Sidney, S. (1997) Seismic Attribute Technology for Reservoir Forecasting and Monitoring. The Leading Edge, 16, 445-456. https://doi.org/10.1190/1.1437657

[4] Taner, M.T., Schuelke, J.S., O’Doherty, R. and Baysal, E. (1994) Seismic Attributes Revisited. 64th Annual International Meeting, Los Angeles, 23 October 1994, 1104-1106. https://doi.org/10.1190/1.1822709

[5] Veeken, P.C.H. (2007) Seismic Stratigraphy, Basin Analysis and Reservoir Characterization. In: Handbook of Geophysical Exploration, Seismic Exploration, Elsevier, Amsterdam, 37, 523 p.

[6] Deng, W.A., Kim, T. and Jang, S. (2018) Seismic Attributes for Characterization of a Heavy-Oil Shaly-Sand Reservoir in the Muglad Basin of South Sudan. Geosciences Journal, 22, 1027-1039. https://doi.org/10.1007/s12303-018-0006-3

[7] Taner, M.T., Koehler, F. and Sheriff, R.E. (1979) Complex Seismic Trace Analysis. Geophysics, 44, 1041-1063. https://doi.org/10.1190/1.1440994

[8] Na'imi, S.R., Shadizadeh, S.R., Riahi, M.A. and Mirzakhanian, M. (2014) Estimation of Reservoir Porosity and Water Saturation Based on Seismic Attributes Using Support Vector Regression Approach. Journal of Applied Geophysics, 107, 93-101. https://doi.org/10.1016/j.jappgeo.2014.05.011

[9] Zeng, H. (2010) Geologic Significance of Anomalous Instantaneous Frequency. Geophysics, 75, 23-30. https://doi.org/10.1190/1.3427638

[10] Raef, A.E., Totten, M., Vohs, A. and Linares, A. (2017) 3D Seismic Reflection Amplitude and Instantaneous Frequency Attributes in Mapping Thin Hydrocarbon Reservoir Lithofacies: Morrison NE Field and Morrison Field, Clark County, KS. Pure and Applied Geophysics, 174, 4379-4394. https://doi.org/10.1007/s00024-017-1664-1

[11] Çemen, I., Fuchs, J., Coffey, B., Gertson, R. and Hager, C. (2014) Correlating Porosity with Acoustic Impedance in Sandstone Gas Reservoirs: Examples from the Atokan Sandstones of the Arkoma Basin, Southeastern Oklahoma. Adapted from Oral 
Presentation Given at the American Association of Petroleum Geologists Annual Convention and Exhibition, Pittsburgh, 19-22 May 2014, 1-17.

[12] Alamsyah, M.N., Handono, B.W. and Syafriya, A. (2016) 3D Seismic Reservoir Characterization and Delineation in Carbonate Reservoir. Extended Abstract Prepared in Conjunction with Oral Presentation at AAPG/SEG International Conference and Exhibition, Melbourne, 13-16 September 2016, 1-14. https://doi.org/10.1190/ice2015-2210675

[13] Kumar, R., Das, B., Chatterjee, R. and Sain, K. (2016) A Methodology of Porosity Estimation from Inversion of Post-Stack Seismic Data. Journal of Natural Gas Science and Engineering, 28, 356-364. https://doi.org/10.1016/j.jngse.2015.12.028

[14] Alao, P.A., Nwoke, C.E., Olabode, S.O. and Ata, A. (2017) Lithology and Porosity Heterogeneity Prediction Using Multiple Seismic Attributes on 3D Surveys: An Example from Edim Oil Field, Niger Delta. International Journal of Advanced Geosciences, 2, 1-6. https://doi.org/10.14419/ijag.v2i1.1594

[15] Inichinbia, S., Sule, P.O., Ahmed, A.L., Hamza, H. and Lawal, K.M. (2014) Petro Physical Analysis of among Hydrocarbon Field Fluid and Lithofacies Using Well Log Data. Journal of Applied Geology and Geophysics, 2, 86-96. https://doi.org/10.9790/0990-02218696

[16] Bello, R., Igwenagu, C.L. and Onifade, Y.S. (2015) Cross Plotting of Rock Properties for Fluid and Lithology Discrimination Using Well Data in a Niger Delta Oil Field. Journal of Applied Sciences and Environmental Management, 19, 539-546. https://doi.org/10.4314/jasem.v19i3.25

[17] Fennita, F., Fitri, N.N., Ajie, H., Adrian, M. and Supriyanto, S. (2017) Reservoir Characterization of Lower Pematang Using Simultaneous Inversion Method in FJ Field, Mallaca Strait Central Sumatra Basin. Proceedings of the 3rd International Symposium on Current Progress in Mathematics and Sciences, Bali, 26-27 July 2017, 1-6. https://doi.org/10.1063/1.5064270

[18] Oliveira, L., Pimentel, F., Peiro, M., Amaral, P. and Christovan, J. (2018) A Seismic Reservoir Characterization and Porosity Estimation Workflow to Support Geological Model Update: Pre-Salt Reservoir Case Study, Brazil. First Break, 36, 1-11.

[19] Ogiesoba, O.C., Ambrose, W.A. and Loucks, R.G. (2018) Application of Instantaneous-Frequency Attribute and Gamma-Ray Wireline Logs in the Delineation of Lithology in Serbin Field, Southeast Texas: A Case Study. Interpretation, 6, T1023-T1043. https://doi.org/10.1190/INT-2018-0067.1

[20] Meldahl, P., Heggland, R., Bril, B. and Groot, P. (2001) Identifying Faults and Gas Chimneys Using Multi Attributes and Neural Networks. The Leading Edge, 20, 474-482. https://doi.org/10.1190/1.1438976

[21] Chambers, R.L. and Yarus, J.M. (2002) Quantitative Use of Seismic Attributes for Reservoir Characterization. CSEG Recorder, 27, 14-25.

[22] Baaske, U.P., Mutti, M., Baioni, F., Bertozzi, G. and Naini, M.A. (2007) Using Multi-Attribute Neural Networks Classification for Seismic Carbonate Facies Mapping: A Workflow Example from Mid-Cretaceous Persian Gulf Deposits. Geological Society, Special Publications, 277, 105-120. https://doi.org/10.1144/GSL.SP.2007.277.01.06

[23] Raeesi, M., Moradzadeh, A., Ardejani, F.D. and Rahimi, M. (2012) Classification and Identification of Hydrocarbon Reservoir Lithofacies and Their Heterogeneity Using Seismic Attributes, Logs Data and Artificial Neural Networks. Journal of Petroleum Science and Engineering, 82-83, 151-165.

https://doi.org/10.1016/j.petrol.2012.01.012 
[24] Kluesner, J.W. and Brothers, D.S. (2015) Seismic Attribute Detection of Faults and Fluid Pathways within an Active Strike-Slip Shear Zone: New Insights from High-Resolution 3D P-Cable ${ }^{\mathrm{Tx}}$ Seismic Data along the Hosgri Fault, Offshore California. Interpretation, 4, SB131-SB148. https://doi.org/10.1190/INT-2015-0143.1

[25] Singh, D., Kumar, P.C. and Sain, K. (2016) Interpretation of Gas Chimney from Seismic Data Using Artificial Neural Network: A Study from Maari 3D Prospect in the Taranaki Basin, New Zealand. Journal of Natural Gas Science and Engineering, 36, 339-357. https://doi.org/10.1016/j.jngse.2016.10.039

[26] Khalid, P., Ahmed, N., Khan, K.A. and Naeem, M. (2014) AVO-Derived Attributes to Differentiate Reservoir Facies from Non-Reservoirs Facies and Fluid Discrimination in Penobscot Area, Nova Scotia. Geosciences Journal, 19, 471-480. https://doi.org/10.1007/s12303-014-0048-0

[27] Castagna, J.P., Swan, H.W. and Foster, D.J. (1998) Framework for AVO Gradient and Intercept Interpretation. Geophysics, 63, 948-956.

https://doi.org/10.1190/1.1444406

[28] Avseth, P., Flesche, H. and Van Wijngaarden, A.J. (2003) AVO Classification of Lithology and Pore Fluids Constrained by Rock Physics Depth Trends. The Leading Edge, 22, 1004-1011. https://doi.org/10.1190/1.1623641

[29] Li, Y., Downtonh, J. and Goodway, B. (2003) Recent Applications of AVO to Carbonate Reservoirs in the Western Canadian Sedimentary Basin. The Leading Edge, 22, 670-674. https://doi.org/10.1190/1.1599694

[30] Nasser, M. (2010) Rock Physics-Modeling Impact of Pore Fluid, Lithology and Depth on AVO Signatures. Society of Exploration Geophysicists Technical Program Expanded Abstracts, Denver, 17-22 October 2010, 373-377. https://doi.org/10.1190/1.3513627

[31] Naeem, M., Jafri, M.K., Moustafa, S.S.R., AL-Arifi, N.S., Asim, S., Khan, F. and Ahmed, N. (2016) Seismic and Well Log Driven Structural and Petrophysical Analysis of the Lower Goru Formation in the Lower Indus Basin, Pakistan. Geosciences Journal, 20, 57-75. https://doi.org/10.1007/s12303-015-0028-Z

[32] Adeoti, L., Adesanya, O.Y., Oyedele, K.F., Afinotan, I.P. and Adekanle, A. (2018) Lithology and Fluid Prediction from Simultaneous Seismic Inversion over Sandfish Field, Niger Delta, Nigeria. Geosciences Journal, 22, 155-169.

https://doi.org/10.1007/s12303-017-0018-4 